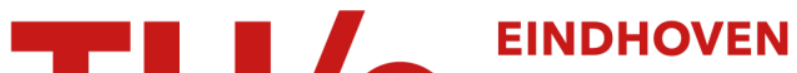 UNIVERSITY OF TECHNOLOGY
}

\section{Wave propagation in thin-walled aortic analogues}

\author{
Citation for published version (APA): \\ Giannopapa, C. G., Kroot, J. M. B., Tijsseling, A. S., Rutten, M. C. M., \& Vosse, van de, F. N. (2009). Wave \\ propagation in thin-walled aortic analogues. (CASA-report; Vol. 0940). Technische Universiteit Eindhoven.
}

\section{Document status and date:}

Published: 01/01/2009

\section{Document Version:}

Publisher's PDF, also known as Version of Record (includes final page, issue and volume numbers)

\section{Please check the document version of this publication:}

- A submitted manuscript is the version of the article upon submission and before peer-review. There can be important differences between the submitted version and the official published version of record. People interested in the research are advised to contact the author for the final version of the publication, or visit the $\mathrm{DOI}$ to the publisher's website.

- The final author version and the galley proof are versions of the publication after peer review.

- The final published version features the final layout of the paper including the volume, issue and page numbers.

Link to publication

\section{General rights}

Copyright and moral rights for the publications made accessible in the public portal are retained by the authors and/or other copyright owners and it is a condition of accessing publications that users recognise and abide by the legal requirements associated with these rights.

- Users may download and print one copy of any publication from the public portal for the purpose of private study or research.

- You may not further distribute the material or use it for any profit-making activity or commercial gain

- You may freely distribute the URL identifying the publication in the public portal.

If the publication is distributed under the terms of Article $25 \mathrm{fa}$ of the Dutch Copyright Act, indicated by the "Taverne" license above, please follow below link for the End User Agreement:

www.tue.nl/taverne

Take down policy

If you believe that this document breaches copyright please contact us at:

openaccess@tue.nl

providing details and we will investigate your claim. 


\section{EINDHOVEN UNIVERSITY OF TECHNOLOGY}

Department of Mathematics and Computer Science

\section{CASA-Report 09-40}

December 2009

\section{Wave propagation in thin-walled} aortic analogues

by

C.G. Giannopapa, J.M.B. Kroot, A.S. Tijsseling, M.C.M. Rutten, F.N. van de Vosse

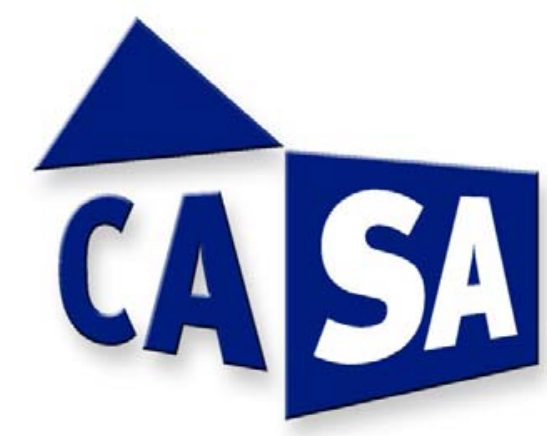

Centre for Analysis, Scientific computing and Applications

Department of Mathematics and Computer Science

Eindhoven University of Technology

P.O. Box 513

5600 MB Eindhoven, The Netherlands

ISSN: 0926-4507 


\title{
WAVE PROPAGATION IN THIN-WALLED AORTIC ANALOGUES
}

\author{
C.G. Giannopapa ${ }^{+}$ \\ A.S. Tijsseling ${ }^{+}$M.C.M. Rutten* $\quad$ F.N. van de Vosse \\ ${ }^{+}$Dept. of Mathematics and Computer Science \\ *Dept. of Biomedical Engineering \\ Eindhoven University of Technology \\ PO Box 513, 5600 MB Eindhoven \\ The Netherlands \\ Email: c.g.giannopapa@tue.nl
}

\begin{abstract}
Research on wave propagation in liquid-filled vessels is often motivated by the need to understand arterial blood flow. Theoretical and experimental investigation of the propagation of waves in flexible tubes has been studied by many researchers. The analytical one-dimensional frequency domain wave theory has a great advantage of providing accurate results without the additional computational cost related to the modern time domain simulation models. For assessing the validity of analytical and numerical models well defined in-vitro experiments are of great importance. The objective of this paper is to present a frequency domain analytical model based on one-dimensional wave propagation theory and validate it against experimental data obtained for aortic analogues. The elastic and viscoelastic properties of the wall are included in the analytical model. The pressure, volumetric flow rate and wall distention obtained from the analytical model are compared with experimental data in two straight tubes with aortic relevance. The analytical results and the experimental measurements were found to be in good agreement when the viscoelastic properties of the wall are taken into account.
\end{abstract}

Key words: Artery, viscoelastic, wave propagation, analytical method, frequency domain, in-vitro experiments

\section{INTRODUCTION}

Wave propagation in liquid filled vessels has been studied for over 200 years and one motivation is to understand arterial blood flow [1-3]. Other studies involve applications in civil, biomedical and mechanical engineering.

The firm basis of theoretical investigation of wave propagation in tubes is related to the work of Womersley [4], even though Young [5] was one of the first investigators interested in understanding the transient motion of fluids in pipes, elastic tubes, conical vessels and blood circulation; see also Tijsseling [6]. During the 1960s there was a large activity in the scientific communities related to analytical solutions of the equations of motion of viscous, incompressible fluids in the frequency domain. This work is summarized by Cox [7]. A lot of questions related to the physiological fluid dynamics were addressed by the work of Lighthill [8].

For the last two decennia with the advancement of scientific computing the interest of the scientific community has shifted towards more complicated two-dimensional and three-dimensional computer simulation time domain models solved using finite elements or finite volumes [9-15]. The major drawback of these methods is increased computational time compared to one-dimensional frequency domain analytical models.

Experimental measurements have been performed to better understand wave propagation phenomena and validate analytical and numerical models. An extensive review of the work in the field is by Tijsseling [16]. Von Kries [17] was one of the first investigators to perform wave propagation experiments in rubber hoses. The work of Klip [18] was the first attempt to validate the Womersley theory. Up until the 
work of Gerrard [19] the Womersley theory [4] had only been tested for tethered tubes. Gerrard was interested in determining the behavior of long tubes where the longitudinal motion was present. In the work of Giannopapa [20] a complete experimental data set measured in aortic analogues was presented.

Most of the experimental work on wave propagation in liquid filled tubes does not consider vessels with wall thickness less than $1 \mathrm{~mm}$ as aortic analogues. This is due to the fact that such tubes, which can produce wave speeds as low as those in the aorta, are not commercially available and need specific manufacturing. However, measurements in thinner wall tubes can provide relevant validation data for computational and analytical methods where the wall thickness to diameter ratio reduces significantly. In Giannopapa [20], tubes with relevant aortic dimensions as provided by Westerhof et al [21] have been manufactured and used in order to obtain pressure, pressure gradient, volumetric flow rate and wall distention measurements.

Predicting and understanding pressure and flows in aortic analogues are of significant importance because they are often used for medical diagnostics related to the cardiovascular system. As the heart beats a pressure wave is initiated due to the injection of a volume of blood into the arterial system. The arteries distend to accommodate the change in volume and the wave propagates along the aorta into main arteries.

The aim of this paper is to present a one-dimensional analytical method for predicting pressure, volumetric flow rate and wall distention and compare it with in-vitro experiments in liquid filled viscoelastic tubes of aortic relevance. The analytical model presented in this paper is based on onedimensional linear theory in the frequency domain for wave propagation in elastic and viscoelastic vessels. The experimental measurements are performed in elastic tubes that have the same dimensions as the aorta but yet without tapering. The wave speed of the traveling wave is of the same order as the one in the aorta. The measured quantities are pressure, volumetric flow rate and wall distention.

\section{MATHEMATICAL FORMULATION}

The theory related to propagation of pressure disturbances in distensible vessels for a circular uniform tube is often referred to as Womersley theory or linear theory and is outlined below.

\section{Linear theory of wave propagation in flexible vessels}

Consider a flexible tube filled with water; see Figure 1. A disturbance in a fluid filled tube propagates as a wave. The wave speed in the fluid is given by the Moens-Korteweg Equation [22].

$$
c=\sqrt{\frac{K}{\rho_{f}}\left(1+\psi \frac{2 r_{0}}{h} \frac{K}{E}\right)^{-1}}
$$

where $K$ is the bulk modulus; $\rho_{f}$ is the mass density of the fluid; $r_{0}$ is the initial radius of the tube; $h$ is the wall thickness; $E$ is the Young's modulus; and $\psi$ is a coefficient that accounts for different longitudinal support conditions for thin-walled and thick-walled tubes. The thin-wall assumption holds when the wall thickness over the inner diameter is less than $1 / 20$. In the case were the tube wall is very flexible $K \gg E$ the Equation (1) reduces to

$$
c_{0}=\sqrt{\psi^{-1} \frac{E h}{2 r_{0} \rho_{f}}}
$$

The momentum equation and the continuity equation for incompressible Newtonian fluids in a uniform elastic tube under the assumption that the flow is axi-symmetric and neglecting body forces can be solved in the frequency domain after linearization. Note that possible developing boundary layers are not considered, because the 1-D calculations are already in good agreement with the measurements, as shown later on.

Momentum equation:

$$
\rho\left(\frac{\partial \mathbf{U}}{\partial t}+\nabla \cdot(\mathbf{U U})\right)=\nabla \cdot \boldsymbol{\sigma}
$$

Continuity equation or mass conservation:

$$
\nabla \cdot \mathbf{U}=0
$$

Here $\mathbf{U}$ stands for the velocity field and $\boldsymbol{\sigma}$ for the stress tensor. These equations form the basis from which Womersley [4] derives his linear theory.

For Newtonian fluids the constitutive equation for the stress tensor $\boldsymbol{\sigma}$ is given by:

$$
\boldsymbol{\sigma}=2 \eta \operatorname{dev}(\dot{\boldsymbol{\varepsilon}})-p \mathbf{I}=\eta\left(\nabla \mathbf{U}+\nabla \mathbf{U}^{T}\right)-p \mathbf{I}
$$

where $\eta$ is the dynamic viscosity, $\dot{\boldsymbol{\varepsilon}}$ is the strain rate tensor, $p$ is the pressure and $\operatorname{dev}($.$) is the deviatoric part of the tensor.$ Substituting (5) into (3) the momentum equation can be rewritten as:

$$
\rho \frac{\partial \mathbf{U}}{\partial t}=\nabla \cdot \eta\left(\nabla \mathbf{U}+\nabla \mathbf{U}^{T}\right)-\rho \nabla \cdot(\mathbf{U U})-\nabla p
$$

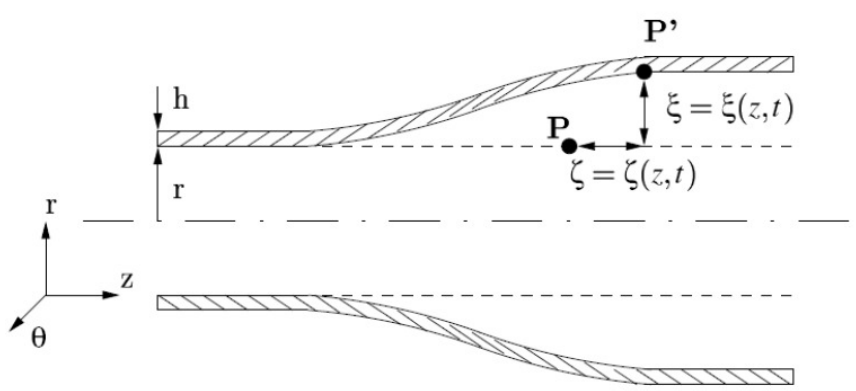

Figure 1: Tube motion variables. Point $P(z, r)$ on the surface of the wall at rest displaces to position $P^{\prime}(z+\zeta, r+\xi)$.

The wave length $\lambda(\lambda=2 \pi c / \omega)$ of the disturbance of interest is assumed to be long compared to the diameter $2 r_{0}$ of the tube $\left(\lambda /\left(2 r_{0}\right)>>1\right)$. It is convenient to make the Navier-Stokes equations non-dimensional. Therefore consider $U_{z}^{*}$ and $U_{r}^{*}$ as typical velocities in the axial $(z)$ and radial $(r)$ direction, respectively. The ratio between the two velocities is defined by $u^{*}=U_{r}^{*} / U_{z}^{*}$ and in the following treatment $u^{*}$ is considered to be small. Provided that $\left|U_{r}^{*} / c\right|<<1$ and $\left|U_{z}^{*} / c\right|<<1$, the convective terms plus all velocity derivatives in the $z$-direction in the momentum equation can be neglected. The non-linear 
form of the Navier-Stokes equations (6) in cylindrical coordinates under axisymmetric conditions ( $\theta$-direction neglected) can therefore be reduced to

$$
\begin{aligned}
& \rho \frac{\partial U_{r}}{\partial t}+\frac{\partial p}{\partial r}=\eta\left[\frac{\partial^{2} U_{r}}{\partial r^{2}}+\frac{1}{r} \frac{\partial U_{r}}{\partial r}-\frac{U_{r}}{r^{2}}\right] \\
& \rho \frac{\partial U_{z}}{\partial t}+\frac{\partial p}{\partial z}=\eta\left[\frac{\partial^{2} U_{z}}{\partial r^{2}}+\frac{1}{r} \frac{\partial U_{z}}{\partial r}\right]
\end{aligned}
$$

The continuity equation in an incrompressible fluid reads

$$
\frac{1}{r} \frac{\partial\left(r U_{r}\right)}{\partial r}+\frac{\partial U_{z}}{\partial z}=0
$$

To be able to integrate over a tube's cross section, appropriate boundary conditions must be specified. At the wall at $r_{0}$, the no-slip and no-leak conditions apply. It is assumed that there is no boundary layer effect (negligible in the sizes used) and no axial movement, a hypothesis which also has an in-vivo relevance in blood flow [23]. Thus,

$$
\left.U_{z}\right|_{r_{0}}=0
$$

Axi-symmetry requires,

$$
\left.U_{r}\right|_{r=0}=\left.\frac{\partial U_{z}}{\partial r}\right|_{r=0}=0
$$

In linear theory, the wave solution can be expressed as a combination of harmonics with angular frequency $\omega$ and wave number $k$. Therefore, each harmonic $\varphi$ (where $\varphi$ can be $p$, $\left.U_{r}, U_{z}\right)$ is of the form

$$
\varphi=\hat{\varphi} e^{i(\omega t-k z)}
$$

In an elastic tube, the propagation constants are functions of the non-dimensional frequency. This non-dimensional frequency is called the Womersley number $\alpha$ which is also known as Stokes number; see e.g. Sarpkaya [24]. It is defined as:

$$
\alpha=r_{0} \sqrt{\frac{\omega \rho}{\eta}}
$$

The combination of the Navier-Stokes equations for the fluid and the equation of motion for the solid including its constitutive equations gives a dispersion equation otherwise called frequency equation; see also [4]. The solution of the frequency equation determines the wave number of propagation $k$ as a function of the mechanical and geometrical properties of the tube, the density and the viscosity of the fluid, and the Womersley number $\alpha$ :

$$
k(\omega)= \pm \frac{\omega}{c_{0}} \sqrt{\frac{1}{1-F_{10}}}
$$

where $c_{0}$ is the wave speed and $F_{10}$ is a function of Womersley parameter $\alpha$ :

$$
F_{10}=\frac{2 J_{1}\left(\alpha i^{3 / 2}\right)}{\alpha i^{3 / 2} J_{0}\left(\alpha i^{3 / 2}\right)}
$$

with $J_{0}$ and $J_{1}$ the Bessel functions of the first kind of order 0 and 1, respectively. The two roots given by Equation (14) are complex numbers and therefore the propagation coefficient $k$ can be expressed as $k=\mathfrak{R}(k)+i \mathfrak{I}(k)$, where the root is chosen such that $\mathfrak{R}(k)>0$. Using this expression for the wave number, the wave speed $c$ and the attenuation constant $\gamma$ are functions of the classical Moens-Korteweg wave speed $c_{0}$ and the real part of the propagation coefficient. Namely,

$$
c=\frac{c_{0}}{\Re(k)}
$$

and the attenuation constant given by

$$
\gamma=\frac{-2 \pi \mathfrak{I}(k)}{\mathfrak{R}(k)}
$$

\section{Wave reflections at closed ends}

The previous section of the theory describes the transmission of a wave in a cylindrical infinitely long tube filled with a fluid with uniform properties. In practice however, a tube has two ends and a finite length. At the ends, the waves will be reflected. This section describes how the reflecting waves can be determined.

A tube of length $L$ is considered starting at $z=-L_{0}$ and ending at $z=L_{1}$ (i.e. $L=L_{0}+L_{1}$ ) as shown in Figure 2. If an input pressure $p_{i}$ is applied at $z=0$ in positive direction, then a wave will travel through the tube and will be reflected at $z=L_{1}$. A continuous harmonic pressure excitation with frequency $\omega$ is assumed.

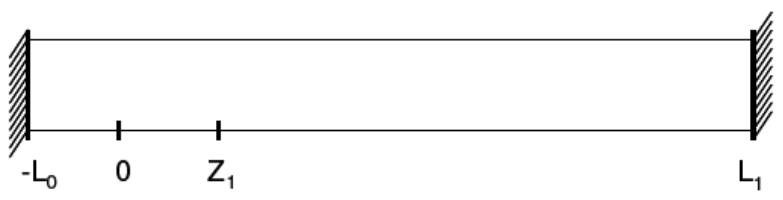

\section{Figure 2: schematic of axial positions of a tube with closed ends, used in the 1-D model.}

The first time this wave arrives at $z=z_{1}$ the pressure is the real part of

$$
p\left(\omega, z_{1}, t\right)=p_{i}(\omega, 0) e^{i\left(\omega t-k z_{1}\right)}
$$

Note that the notation of taking the real part is omitted in this equation, as well as in all following equations, for the sake of readability. At $z=L_{1}$ the pressure due to the wave is

$$
p\left(\omega, L_{1}, t\right)=p_{i}(\omega, 0) e^{i\left(\omega t-k L_{1}\right)}
$$

The wave is reflected at the distal closed end. Let the reflection parameter be denoted by $\Gamma_{1}$. The reflected wave travels in the negative direction and at $z=z_{1}$ the pressure is

$$
p\left(\omega, z_{1}, t\right)=p_{i}(\omega, 0) \Gamma_{1} e^{i\left(\omega t-k\left(2 L_{1}-z_{1}\right)\right)}
$$

When this wave reaches $z=-L_{0}$ the pressure is

$$
p\left(\omega,-L_{0}, t\right)=p_{i}(\omega, 0) \Gamma_{1} e^{i\left(\omega t-k\left(2 L-L_{0}\right)\right)}
$$

and the wave gets reflected again due to the proximal closed end. Let the reflection parameter be denoted by $\Gamma_{0}$. When the reflected wave reaches $z=z_{1}$ for the third time, the pressure is

$$
p\left(\omega, z_{1}, t\right)=p_{i}(\omega, 0) \Gamma_{0} \Gamma_{1} e^{i\left(\omega t-k\left(2 L+z_{1}\right)\right)}
$$

This process continues. The pressure perturbation in the tube is the sum of all reflected waves.

$$
p\left(\omega, z_{1}, t\right)=p_{i}(\omega, 0) e^{i\left(\omega t-k z_{1}\right)}
$$


$\cdot\left[1+\Gamma_{1} e^{-2 i k\left(L-L_{0}-z_{1}\right)}+\Gamma_{0} \Gamma_{1} e^{-2 i k L}+\Gamma_{0} \Gamma_{1}^{2} e^{-2 i k\left(2 L-L_{0}-z_{1}\right)}+\ldots\right]$

or, for recursive purpose

$$
\begin{gathered}
p\left(\omega, z_{1}, t\right)=p_{i}(\omega, 0) e^{i\left(\omega t-k z_{1}\right)} \\
\cdot\left[1+\Gamma_{1} e^{-2 i k\left(L_{1}-z_{1}\right)}\left(1+\Gamma_{0} e^{-2 i k\left(L_{0}+z_{1}\right)}\left(1+\Gamma_{1} e^{-2 i k\left(L_{1}-z_{1}\right)}(\ldots)\right)\right)\right]
\end{gathered}
$$

Assembling the terms that represent waves in positive direction and, separately, those representing waves in negative direction, the expression for pressure can be written as

$$
p\left(\omega, z_{1}, t\right)=p_{i}(\omega, 0) e^{i\left(\omega t-k z_{1}\right)} \frac{1+\Gamma_{1} e^{-2 i k\left(L_{1}-z_{1}\right)}}{1-\Gamma_{0} \Gamma_{1} e^{-2 i k L}}
$$

Here, the geometric series expansion of $1 /(1-x)$ is used. This is a general result. For the special case of total reflection at the two ends $\Gamma_{0}=\Gamma_{1}=1$ holds and

$$
p\left(\omega, z_{1}, t\right)=p_{i}(\omega, 0) e^{i\left(\omega t+k L_{0}\right)} \frac{\cos k\left(L_{1}-z_{1}\right)}{i \sin k L}
$$

The volumetric flow rate $\dot{Q}$ follows directly from (23) by taking into account the direction of the propagation:

$$
\begin{aligned}
& \dot{Q}\left(\omega, z_{1}, t\right)=\dot{Q}_{i}(\omega, 0) e^{i\left(\omega t-k z_{1}\right)} \\
& {\left[1-\Gamma_{1} e^{-2 i k\left(L-L_{0}-z_{1}\right)}+\Gamma_{0} \Gamma_{1} e^{-2 i k L}-\Gamma_{0} \Gamma_{1}^{2} e^{-2 i k\left(2 L-L_{0}-z_{1}\right)}+\ldots\right]}
\end{aligned}
$$

Here $\dot{Q}_{i}(\omega, 0)$ represents the input volumetric flow rate. For the special case of total reflection this yields

$$
\dot{Q}\left(\omega, z_{1}, t\right)=\dot{Q}_{i}(\omega, 0) e^{i\left(\omega t+k L_{0}\right)} \frac{\sin k\left(L_{1}-z_{1}\right)}{\sin k L}
$$

Using a linear elastic material law based on thin walled cylinder theory, the cross-sectional area changes according to

$$
\frac{\partial A}{\partial t}=C_{0} \frac{\partial p}{\partial t}
$$

with $C_{0}$ the compliance per unit of length of the vessel

$$
C_{0}=\frac{2 \pi\left(1-v^{2}\right) r^{3}}{h E}
$$

and $v$ the Poisson ratio. Thus, the cross-sectional area can be derived from the pressure by

$$
A\left(\omega, z_{1}, t\right)=A_{0}\left(\omega, z_{1}\right)+C_{0}\left(p\left(\omega, z_{1}, t\right)-p_{0}\left(\omega, z_{1}\right)\right)
$$

with subscript denoting the initial state, and herewith also the wall distension.

\section{PHYSICAL EXPERIMENTS}

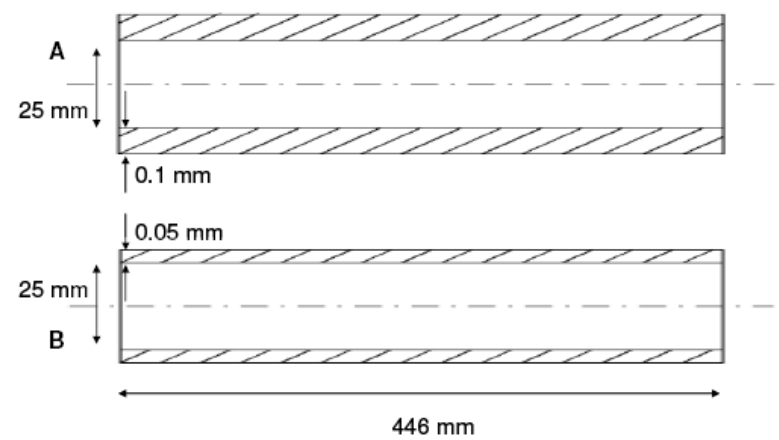

Figure 3: Polyurethane vessels.

\section{Vessels design and specifications}

The vessels were designed to be analogues of the human aorta. One of the most referenced sources for arterial dimensions is that of Westerhof et al [21]. According to their measurements in the human aorta the ratio of Young's modulus multiplied by the thickness of the arterial wall over the arterial lumen diameter was used. For this paper, two straight vessels were manufactured, of which the dimensions can be seen in Figure 3. The vessels were manufactured by spin coating using a solution of polyurethane (PU, Desmopan 588, Bayer, Germany) dissolved in tetrahydrofurane (THF, BASF, Germany). To measure the material properties of the vessels relaxation tests were performed. The stress versus the dimensionless time is shown in Figure 4.

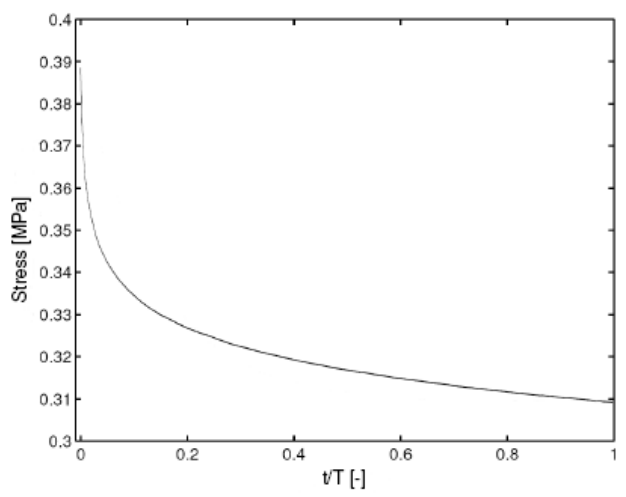

Figure 4: Relaxation test (3\% elongation).

The complex viscoelastic modulus of the material can be written as a function of the angular frequency

$$
\hat{E}(\omega)=\tilde{c} \Gamma(1-n) \omega^{n} e^{n \pi i / 2}
$$

where $\Gamma$ is the gamma function and the values of $\tilde{c}$ and $n$ are obtained by fitting a power law model with the relaxation data and are found to be $1.3\left[\mathrm{~Pa} / \mathrm{s}^{\mathrm{n}}\right]$ and $0.065[-]$, respectively.

\section{Experimental set-up}

A schematic diagram of the experimental set-up used to carry out the wave propagation experiments in flexible vessels is shown in Figure 5. The apparatus consists of: open container filled with water $(\mathrm{E})$; closed container at constant pressure 1 bar (C); open container (D); two-way manually operated solenoid valve (A); three-way PC operated solenoid valve (B) and a vessel $(\mathrm{F})$. The vessel is placed in horizontal position inside the container E. The water column above the vessel prescribes the static pressure outside the vessel. The vessel is pre-strained axially to $3 \%$. The vessel is fixed on both sides against axial movement, whereas it can freely expand in the radial direction. The vessel is connected on one side via the three-way solenoid valve either to container $\mathrm{C}$ or container $\mathrm{D}$. When the solenoid valve is not engaged the vessel is connected to the open tank (D) which prescribes the initial pressure inside the vessel. By engaging the solenoid valve it opens for $50 \mathrm{~ms}$ and generates a pulse by introducing a propagating pressure wave. The sensors used are typical for in in-vivo clinical measurements. The pressure inside the vessel is measured simultaneously by two pressure sensors (Radi Medical Systems 12000XT), $17 \mathrm{~mm}$ apart. By using two simultaneous pressure measurements the pressure gradient is obtained. The volumetric flow rate is measured using a perivascular flow rate sensor (MC28AX, 
Transonic, The Netherlands). The wall motion is measured using an ultrasound wall tracking system [25].

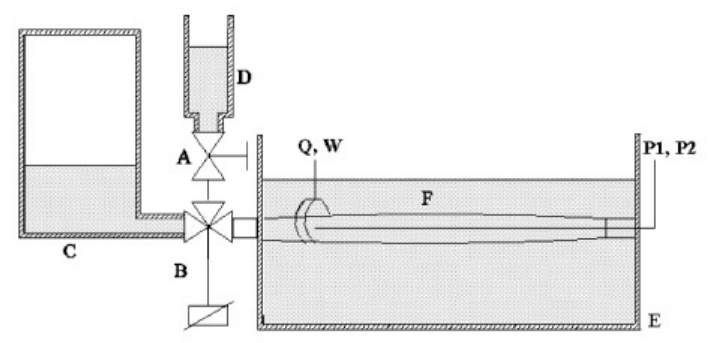

Figure 5: Experimental set-up.

\section{RESULTS}

The vessels are preloaded at $2.94 \mathrm{kPa}$ relative to the pressure outside the vessel and during measurement the twoway solenoid valve is kept closed to preserve the volume of water induced in the vessel by the $50 \mathrm{~ms}$ opening of the valve. To ensure that the vessel undergoes small deformations, it was inflated by inducing known amounts of fluid and with diameter static pressure measurements it was concluded that the corresponding strains are less than $3 \%$ and consequently may be considered as small.

Measurements of pressure, volumetric flow rate and wall distention were performed at 10 locations along the vessel $z=$ $\left[\begin{array}{llllllllll}0.03 & 0.05 & 0.1 & 0.15 & 0.2 & 0.25 & 0.3 & 0.35 & 0.4 & 0.45\end{array}\right] \mathrm{m}$. Every measurement was repeated 16 times for statistical evaluation of the reliability and reproducibility of the measured data. The standard deviation was determined and it was found to be of the order of the signal to noise ratio. The volume increase in the vessel by the engagement of the solenoid valve was $2.57 \mathrm{ml}$.

The anchoring of the tubes is throughout against axial movement so $\psi=1-v^{2}$ where $v$ is the Poisson ratio and for vessels $\mathrm{A}$ and $\mathrm{B}$ it is assumed that $v=0.5$. The wave velocities in tubes $\mathrm{A}$ and $\mathrm{B}$ are $c_{0} \approx 9 \mathrm{~m} / \mathrm{s}$ and $6 \mathrm{~m} / \mathrm{s}$, respectively. The analytical results were obtained using the fluid parameters $\rho=998 \mathrm{~kg} / \mathrm{m}^{3}, \eta=1.04 \cdot 10^{-3} \mathrm{~kg} / \mathrm{ms}$. The initial 3\% axial prestrain is taken into account in the analytical model.

Figures 6 and 7 show the experimental results obtained from the measurements for vessel A against the analytical results. Vessel A has a wall thickness of $0.1 \mathrm{~mm}$ and wave velocity of $c_{0} \approx 9 \mathrm{~m} / \mathrm{s}$. This velocity has been verified by the measurements, after determining the axial distance travelled by the pulse per second. The experimental results are the same in both figures. The difference is in the analytical model: Figure 6 represents an elastic wall, whereas Figure 7 represents a viscoelastic wall. The measurements of the pressure sensors, volumetric flow rate meter, and ultrasound wall distention for $0.5 \mathrm{~s}$ are shown for each of the 10 locations $z$ along the tube. The viscoelasticity of the wall is evident in the measurements by the attenuation of the waves. The propagation of pressure, volumetric flow rate and wall expansion for the accommodation of the traveling wave through the vessel can be identified by the time difference between the pulse arrival at $z=0.03 \mathrm{~m}$ and at $z=0.45 \mathrm{~m}$. At location $z=0.45 \mathrm{~m}$ the amplitude of the pressure pulse has almost doubled because of the interference of the forward and the backward traveling wave. Nine reflections in $0.5 \mathrm{~s}$ can be clearly identified. The direction of the flow alters every time the wave is reflected at one of the ends and it is indicated by the positive and the negative sign in the flow measurements. The pressure signal is at all times positive due to the full reflection at the closed ends. The wall distention signal follows the pressure signal. It is also at all times positive as the wall expands from its original position driven by the pressure.

In Figure 6 the analytical theory of an elastic vessel of the same dimensions as vessel A, with Young's modulus 17.2 $\mathrm{MPa}$, is compared with the experimental data. If an elastic wall is considered the analytical theory is not sufficient to predict the propagating wave. This is expected due to the fact that the amplitude of the waves is damped significantly in the experimental measurements mainly due to the vessels viscoelasticity. The analytical results of the elastic wall help to clearly identify the forward and the backward traveling waves during the multiple reflections.

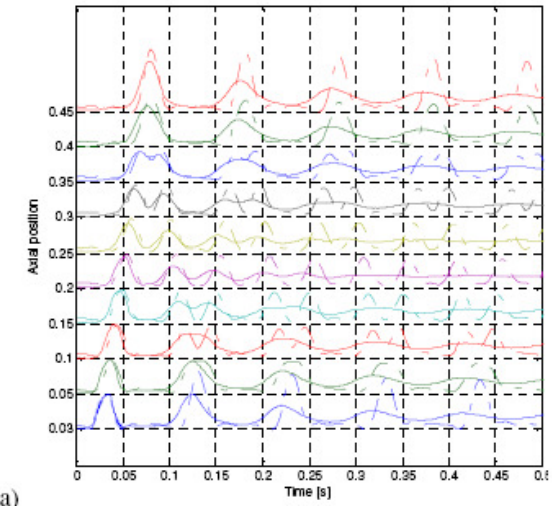

(a)

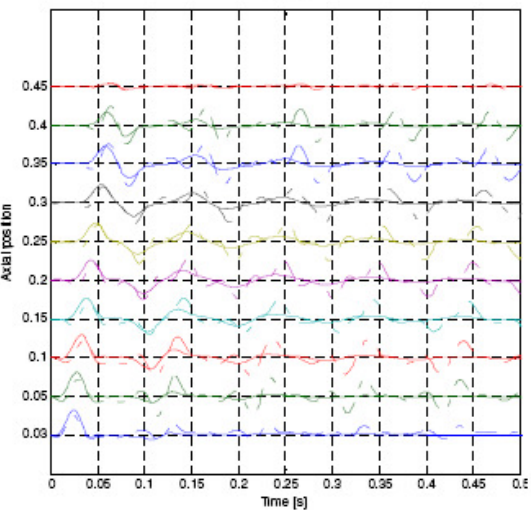

(b)

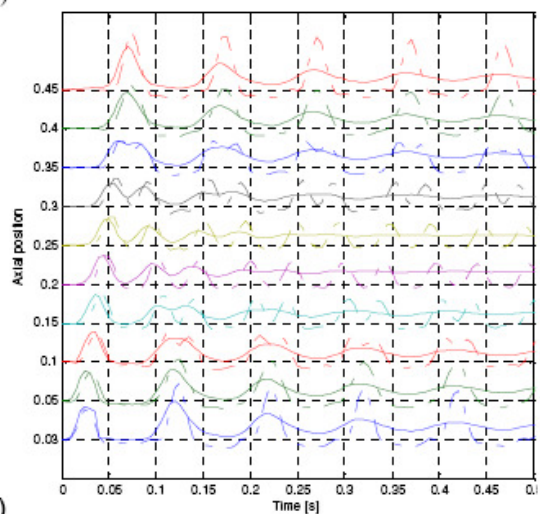

Figure 6: Vessel A. Solid line experimental data, dashed line analytical solution for elastic wall. (a) Pressure [Pa]; (b) Flow rate $\left[\mathrm{m}^{3} / \mathrm{s}\right]$; (c) Wall distention $[\mu \mathrm{m}]$. 


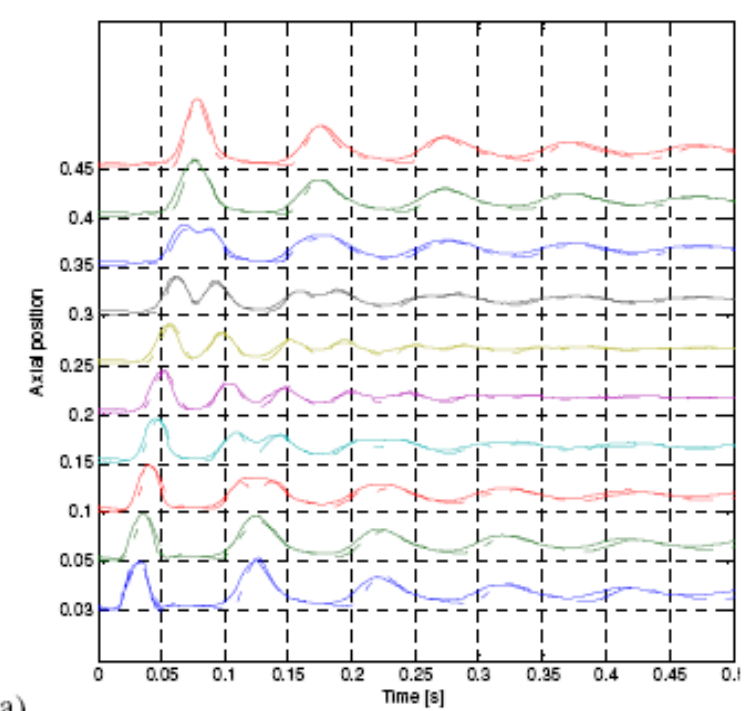

(a)

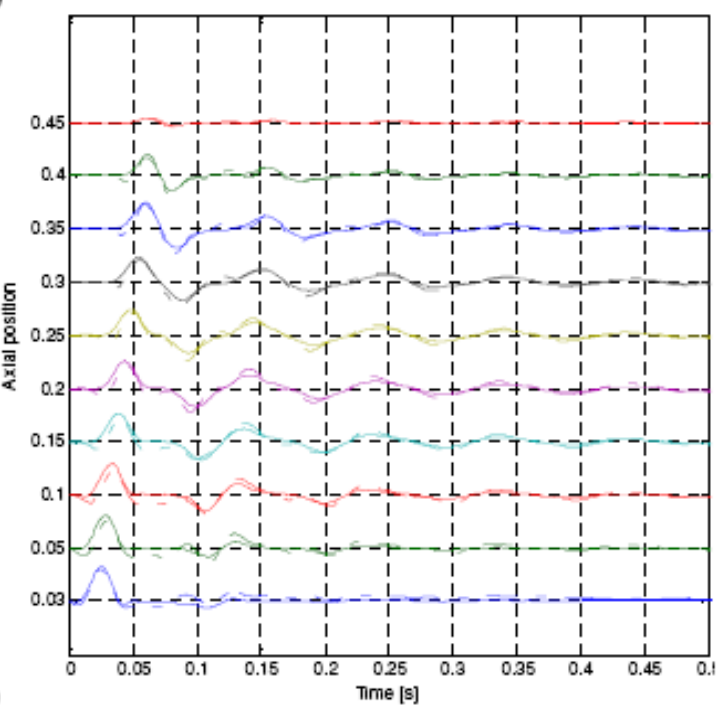

(b)

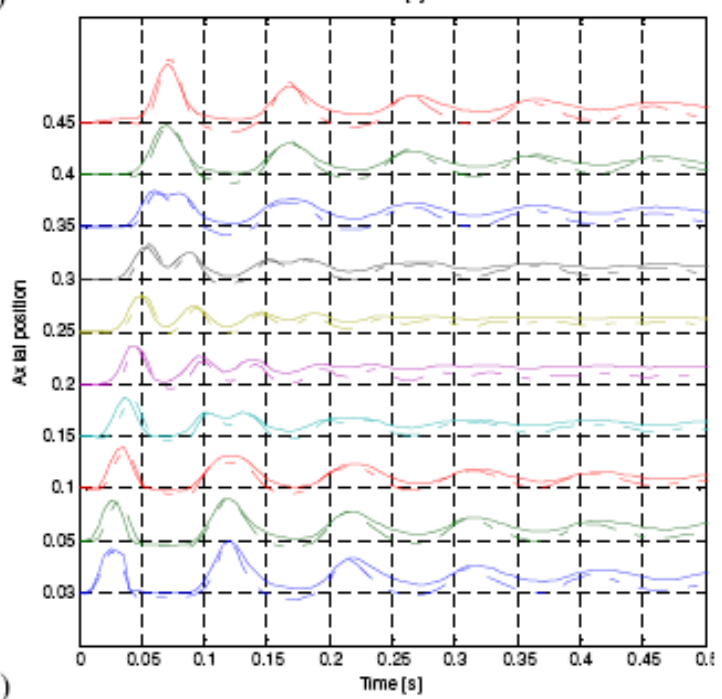

Figure 7: Vessel A. Solid line experimental data, dashed line analytical solution for viscoelastic wall. (a) Pressure [Pa]; (b) Flow rate $\left[\mathrm{m}^{3} / \mathrm{s}\right]$; (c) Wall distention $[\mu \mathrm{m}]$.

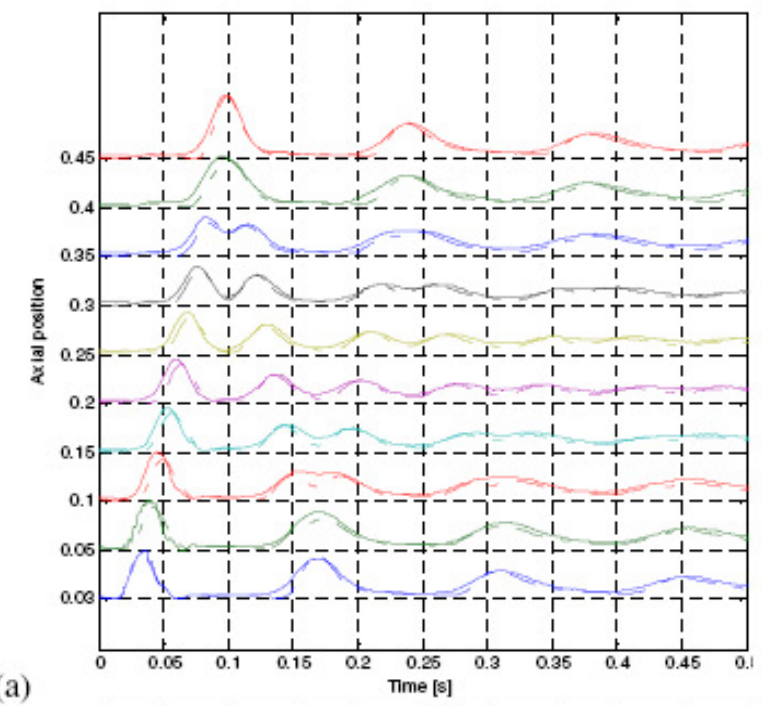

(a)

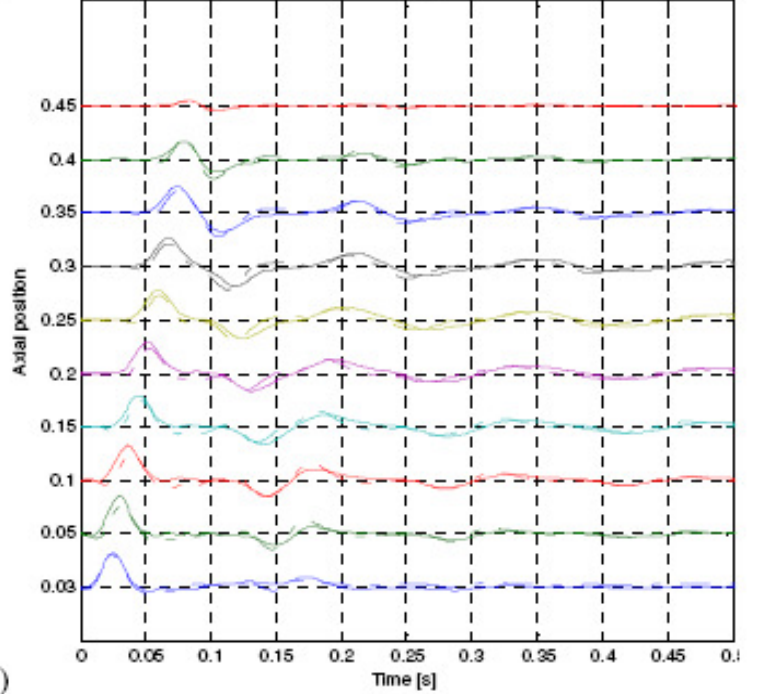

(b)

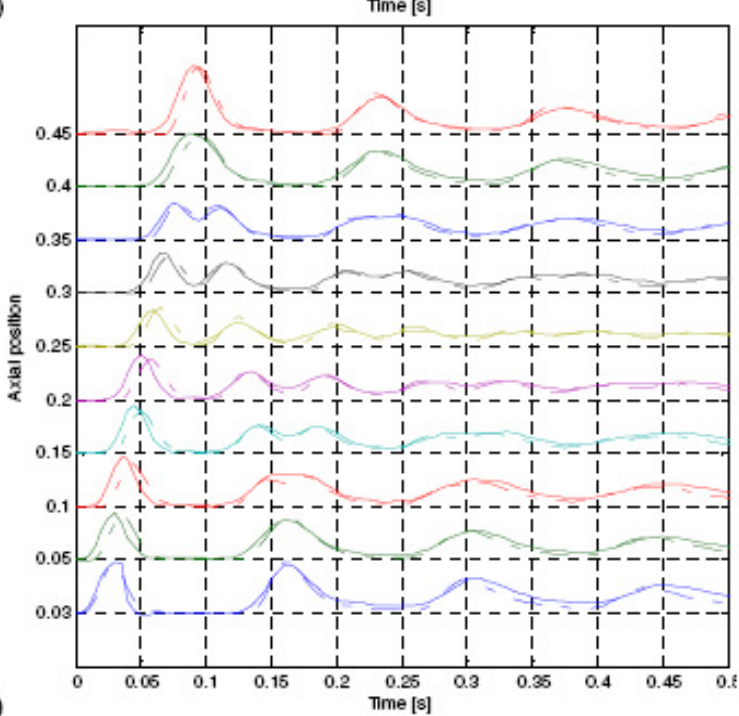

Figure 8: Vessel B. Solid line experimental data, dashed line analytical solution for viscoelastic wall. (a) Pressure [Pa]; (b) Flow rate $\left[\mathrm{m}^{3} / \mathrm{s}\right]$; (c) Wall distention $[\mu \mathrm{m}]$. 
In Figure 7 the results of the analytical theory for a viscoelastic vessel are presented, with material properties as obtained by the relaxation test using the complex Young's modulus (32) and the same dimensions as vessel A. The results are compared with the experimental data for vessel A and show to be in close agreement. Small deviations between experimental and analytical data can be related to the accuracy of the fitting of the material properties of the wall. Pressure is shown in Figure 7a, volumetric flow rate in Figure $7 \mathrm{~b}$ and the wall distention in Figure 7c.

In Figure 8 the comparison between the analytical solution and the experimental measurements obtained from viscoelastic vessel $\mathrm{B}$ are obtained. Vessel $\mathrm{B}$ has a wall thickness of 0.05 $\mathrm{mm}$ and wave velocity $c_{0} \approx 6 \mathrm{~m} / \mathrm{s}$, which has also been verified by the measurements. The pressure, volumetric flow rate and wall distention are shown in Figures $8 \mathrm{a}, \mathrm{b}$ and $\mathrm{c}$, respectively. The comparison between the analytical solution and the experimental data is in close agreement. The agreement between the analytical solution and the measurements is better for the thinner vessel $\mathrm{B}$ as the influence of the error related to the material properties is smaller.

\section{CONCLUSIONS}

In this paper a frequency domain analytical model based on one-dimensional wave propagation theory was presented and compared with experimental measurements. The analytical model is able to predict pressure waves, volumetric flow rate and wall distention. New experimental measurements of pressure, volumetric flow rate and wall distention were performed in very thin-wall vessels that are aortic analogues having wave speeds similar to those found in the human aorta. The predictions of the one-dimensional analytical model were in good agreement with the experimental measurements giving confidence that it can be used for predicting waves in blood flow research. Moreover, the experiments are new and useful to others.

\section{ACKNOWLEDGMENTS}

The authors would like to thank Marie Curie Research Training Networks Fellowships, European Commission, and EPSRC, UK for partially funding this project.

\section{REFERENCES}

[1] Lighthill, J., 1978. Waves in fluids. Cambridge University Press, Cambridge, UK

[2] Fung, Y.C., 1984. Biodynamics: circulation. New York, Springer.

[3] Fung, Y.C., 1997. Biomechanics: circulation. New York, Springer.

[4] Womersley, J.R., 1957. An elastic tube theory of pulse transmission and oscillatory flow in mammalian arteries. Technical report WADC-TR-56-614, Wright Air Development Center, Dayton USA.

[5] Young, T., 1808. Hydraulic investigations, subservient to an intended Croonian lecture of the motion of blood. Philosophical Transactions of the Royal Society (London), 98: 164-186.

[6] Tijsseling, A.S., and Anderson, A., 2008. Thomas Young's research on fluid transients: 200 years on. BHR Group 2008 Pressure Surges, 10: 21-33.

[7] Cox, R., 1968. Wave propagation through a Newtonian fluid contained within a thick-walled viscoelastic tube. Biophysical Journal, 8: 691-709.
[8] Lighthill, M.J., 1972. Physiological fluid dynamics: a survey. J. Fluid Mech. 52: 475-497.

[9] Giannopapa, C.G., 2009. Development of the monolithic unified single solution method for fluid structure interaction problems, Journal of Computational and Nonlinear Dynamics, accepted.

[10] Heil, M., 1998. Stokes flow in an elastic tube - a large displacement fluid-structure interaction problem. Int. J. Numer. Meth. Fluids 28: 243-265.

[11] Perktold, K. Rappitsch, G., 1995. Computer simulation of local blood flow and vessel mechanics in a compliant carotid artery bifurcation model. Journal of Biomechanics, 28(7): 845856.

[12] Taylor, C.A., Hughes, T.R., Zarins, C.K., 1998. Finite element modeling of blood flow in arteries. Computer Methods in Applied Mechanics and Engineering, 158: 155-196.

[13] Wan, J., Steele, B., Spicer, S.A, Strohband, S., Feeijoo, C.R., Hughes, T.R., 2002. A one-dimensional finite element method for simulation based medical planning for cardiovascular disease. Computer Methods in Biomechanics and Biomedical Engineering, 5(3): 195-206.

[14] Vignon-Clementel, I.E., Figueroa, C.A., Jansen, K.E., Taylor, C.A., 2006. Outflow boundary conditions for threedimensional finite element modeling of blood flow and pressure in arteries. Comput. Methods Appl. Mech. Engrg. 195: 3776-3796.

[15] Johnston, B.M., Johnston, P.R., Corney, S., Kilpatrick, D., 2004. Non-Newtonian blood flow in human right coronary arteries: steady state simulations. Journal of Biomechanics, 37: 709-720.

[16] Tijsseling, A.S., 1996. Fluid-structure interaction in liquid filled pipe systems: a review. Journal of Fluids and Structures, 10: 109-146.

[17] von Kries, J., 1892. Studien zur Pulslehre. Akademische Verlagsbuchhandlung von JCB Mohr (Paul Siebeck), Freiburg, Germany.

[18] Klip, W., 1962. Velocity and damping of pulse waves. Martinus Nijhoff, The Hague, The Netherlands.

[19] Gerrard, J.H., 1985. An experimental test of the theory of waves in fluid-filled deformable tubes. Journal of Fluid Mechanics, 156: 321-347.

[20] Giannopapa, C.G., 2004. Fluid-structure interaction in flexible vessels. $\mathrm{PhD}$ thesis, University of London, UK.

[21] Westerhof, N., Bosman, F., Vries, C.J.D., and Noordergraaf, A. 1969. Analogue studies of the human systematic arterial tree. Journal of Biomechanics, 2: 121-143.

[22] Korteweg, D.J., 1878. Uber die Fortpflanzungs geschwindigkeit des Schalles in elastischen Rohren. Annalen der Physik und Chemie, 5: 525-542.

[23] Pedley, T.J., 1980. The fluid mechanics of large blood vessels. London: Cambridge University Press.

[24] Sarpkaya, T., 2005. On the parameter $\beta=\operatorname{Re} / K C=D^{2} / v T$. Journal of Fluids and Structures, 21: 435-440.

[25] Brands, P.J., Hoeks, A.P.G, Willigers, J., and Willekes, C., 1999. An integrated system for the non-invasive assessment of vessel wall and homodynamic properties of large arteries by means of ultrasound. European Journal of Ultrasound, 9: 257266. 
PREVIOUS PUBLICATIONS IN THIS SERIES:

\begin{tabular}{|c|c|c|c|}
\hline Number & Author(s) & Title & Month \\
\hline $09-36$ & $\begin{array}{l}\text { A. Mikelić } \\
\text { C.J. van Duijn }\end{array}$ & $\begin{array}{l}\text { Rigorous derivation of a } \\
\text { hyperbolic model for Taylor } \\
\text { Dispersion }\end{array}$ & Nov. '09 \\
\hline $09-37$ & $\begin{array}{l}\text { E.J.W. ter Maten } \\
\text { T.S. Doorn } \\
\text { J.A. Croon } \\
\text { A. Bargagli } \\
\text { A. Di Bucchianico } \\
\text { O. Wittich }\end{array}$ & $\begin{array}{l}\text { Importance sampling for high } \\
\text { speed statistical Monte-Carlo } \\
\text { simulations }\end{array}$ & Nov. '09 \\
\hline $09-38$ & $\begin{array}{l}\text { J. Rommes } \\
\text { P. Lenaers } \\
\text { W.H.A. Schilders }\end{array}$ & $\begin{array}{l}\text { Reduction of large resistor } \\
\text { networks }\end{array}$ & Nov. '09 \\
\hline 09-39 & $\begin{array}{l}\text { T.S. Doorn } \\
\text { J.A. Croon } \\
\text { E.J.W. ter Maten } \\
\text { A. Di Bucchianico }\end{array}$ & $\begin{array}{l}\text { A yield centric statistical } \\
\text { design method for } \\
\text { optimization of the SRAM } \\
\text { active column }\end{array}$ & Dec. '09 \\
\hline $09-40$ & $\begin{array}{l}\text { C.G. Giannopapa } \\
\text { J.M.B. Kroot } \\
\text { A.S. Tijsseling } \\
\text { M.C.M. Rutten } \\
\text { F.N. van de Vosse }\end{array}$ & $\begin{array}{l}\text { Wave propagation in thin- } \\
\text { walled aortic analogues }\end{array}$ & Dec. '09 \\
\hline
\end{tabular}

